\title{
GROUND TESTING A 20-METER INFLATION DEPLOYED SOLAR SAIL
}

\author{
Troy Mann ${ }^{*}$ and Vaughn Behun ${ }^{\dagger}$ \\ Swales Aerospace, Hampton, VA, 23681 \\ David Lichodziejewski ${ }^{\ddagger}$ and Billy Derbes ${ }^{\S}$ \\ L'Garde Inc.,Tustin, CA, 92780 \\ David Sleight $^{* *}$ \\ NASA Langley Research Center, Hampton, VA 23681
}

\begin{abstract}
Solar sails have been proposed for a variety of future space exploration missions and provide a cost effective source of propellantless propulsion. Solar sails span very large areas to capture and reflect photons from the Sun and are propelled through space by the transfer of momentum from the photons to the solar sail. The thrust of a solar sail, though small, is continuous and acts for the life of the mission without the need for propellant. Recent advances in materials and ultra-low mass gossamer structures have enabled a host of useful space exploration missions utilizing solar sail propulsion. The team of L'Garde, NASA Jet Propulsion Laboratory (JPL), Ball Aerospace, and NASA Langley Research Center, under the direction of the NASA In-Space Propulsion Office (ISP), has been developing a scalable solar sail configuration to address NASA's future space propulsion needs. The 100-m baseline solar sail concept was optimized around the one astronomical unit (AU) Geostorm mission, and features a Mylar sail membrane with a striped-net sail suspension architecture with inflation-deployed sail support beams consisting of inflatable sub- $\mathbf{T}_{\mathrm{g}}$ (glass transition temperature) rigidizable semi-monocoque booms and a spreader system. The solar sail has vanes integrated onto the tips of the support beams to provide full 3-axis control of the solar sail. This same structural concept can be scaled to meet the requirements of a number of other NASA missions. Static and dynamic testing of a $20 \mathrm{~m}$ scaled version of this solar sail concept have been completed in the Space Power Facility (SPF) at the NASA Glenn Plum Brook facility under vacuum and thermal conditions simulating the operation of a solar sail in space. This paper details the lessons learned from these and other similar ground based tests of gossamer structures during the three year solar sail project.
\end{abstract}

\section{Introduction}

C OLAR sails provide unique opportunities in space mission design because of their ability to provide constant $\checkmark$ accelerations without the need for large propellant reserves ${ }^{1-4}$. This allows for quick transit for extra-solarsystem missions and for unique station-keeping orbits that are otherwise difficult to achieve (e.g. Geostorm ${ }^{5-6}$ ). Solar sails rely on very large areas to capture and reflect solar photons. In order to achieve propulsive efficiencies that make them attractive for mission designers, they must also have very small areal densities. The requirements for large areas and small areal densities lead to structures that are designed solely for space operations. As in virtually all ground based tests of structures for space operations, some sort of ground operations interface is required. However, the gossamer nature of solar sails complicates ground testing significantly as the ground operations interfaces can become cumbersome and potentially limiting in attempts to advance the technology readiness levels (TRL) of candidate technologies.

\footnotetext{
* Aerospace Engineer, M/S 230, AIAA Member.

${ }^{\dagger}$ Aerospace Engineer, M/S 230, AIAA Member.

‡ Aerospace Engineer, AIAA Member

$\S$ Aerospace Engineer, AIAA Member

** Aerospace Engineer, Computational Structures and Methods Branch/Research \& Technology Directorate, MS 155, AIAA Member
} 
L'Garde has designed and developed a 20 meter subscale solar sail ground technology demonstrator through a multi-year program funded by the InSpace Propulsion (ISP) office of the Marshall Space Flight Center. The 20 meter subscale system represents a scaled model of a full $100 \mathrm{~m}$ class solar sail vehicle (see Figure 1). Three phases of the program allowed for design, development, and validation testing of component technologies (Phase I), subsystem technologies (Phase II), and sub-scale system demonstration (Phase III). The structural validation of these three phases was carried out by NASA Langley's Structural Dynamics Branch at several different facilities. The three phases of the program required more and more sophisticated instrumentation, data acquisition techniques, and data analysis. This paper presents the lessons learned through the various test programs carried out through the course of the multi-year program.

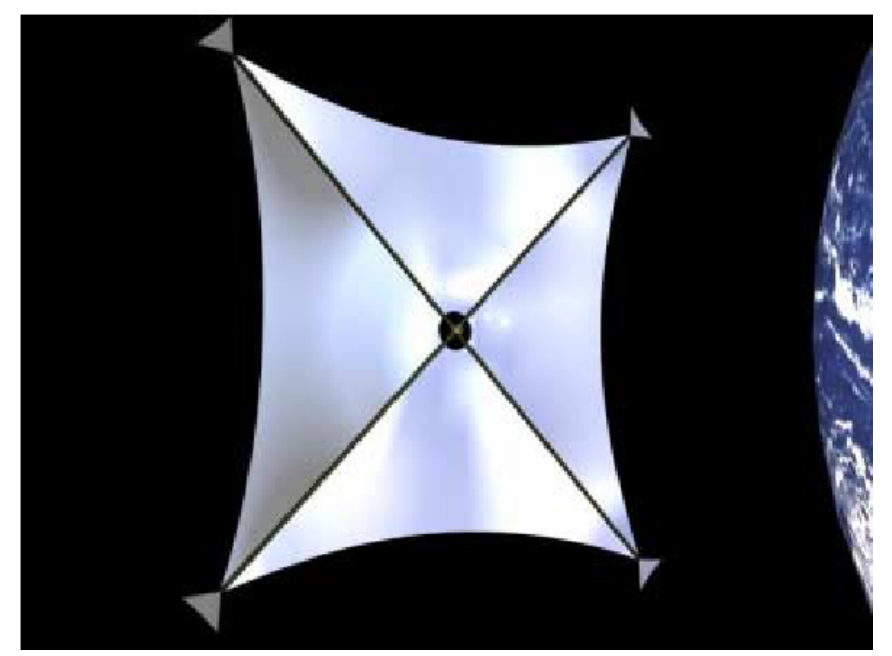

Figure 1. L'Garde’s 100m Solar Sail System Design

\section{Phase I - Component Testing}

The L'Garde design for the 100m Geostorm mission featured a sail net/membrane with a striped sail suspension and inflation-deployed beams. The beams were rigidized following deployment using a sub- $\mathrm{T}_{\mathrm{g}}$ rigidizable material in the matrix ${ }^{6-10}$. The material rigidization scheme takes advantage of the cold temperatures of space for increasing modulus of the beam material. However, this also requires all ground testing to operate at these temperatures in order to successfully measure representative structural characteristics.

Small sections of the beam material were measured in the NASA Langley Cold Rigidizable Testing Facility (see Figure 2) - an enclosed chamber for the testing of inflatable, deployable, and cold rigidizable structures. The facility is designed to hold specimens up to 3 meters in length and can control the interior temperature to $-50 \mathrm{C}$. The cold box is designed to study the compressive stiffness, compressive failure, tension stiffness, and bending stiffness

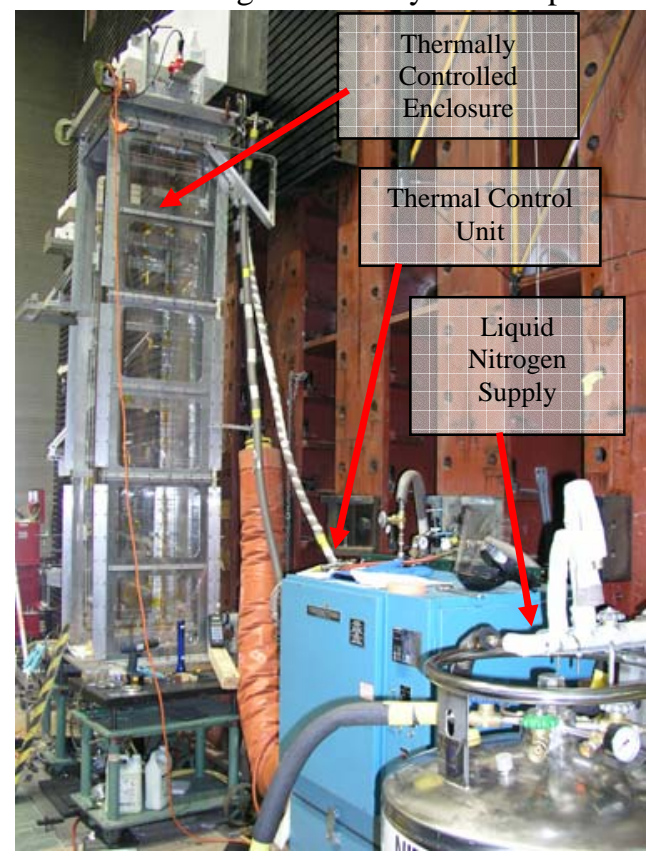

Figure 2. LaRC Cold Rigidizable Column Testing Facility of slender lightweight columns. Three $0.8 \mathrm{~m}$ columns were successfully measured for compressive stiffness and compressive failure.

A single 3m column was fabricated for testing in the same manner. Additionally, the tension stiffness and torsional stiffness were also to be measured. While these tests were successful, they were not without incident. During virtually all of the ground based testing that took place during the solar sail project, it became clear that typical fixture design can often become troubling when coupled with extremely light-weight structures such as these. The $3 \mathrm{~m}$ column test provided the first evidence of this.

A lightweight end cap was built by L'Garde to enclose the column volume for pressurization during the rigidization process. This was mounted to pre-existing end fixtures to mount the column in the test enclosure. However, the end fixtures were designed and built for stiffer structures and were significantly heavier than the loads intended for application to the structure. As a result, the tension and compression tests required off-loading of the end fixtures in order to apply the much lower loads. This proved relatively simple for the tension and compression tests, but was more troublesome for the torsion tests.

The torsion loads for the torsional stiffness test were to be applied by a dead-weight system attached to the perimeter of the attachment fixture. Unfortunately, the small loads applied in torsion 
(to simulate the small operating loads) were incapable of overcoming the friction in the system. In order to measure the torsional stiffness, therefore, a dynamic torsion test was performed. Accelerometers were attached to the perimeter of the attachment fixture and the system was excited dynamically to determine the first torsion frequency of the structure. Normally, this could be simply related to the analytical solution for a column with a mass attached to determine the torsional stiffness of the column. However, the mass of the attachment fixture was significant enough to violate the assumptions regarding the axial stress state of the column in the analytical derivation. As a result, a finite element model of the test setup was required to successfully determine the torsional stiffness of the column.

\section{Phase II - Sub-System Testing}

During Phase II of the solar sail program, a 7 meter beam and a 4-quadrant solar sail were fabricated for deployment and structural characterization. The 7 meter beam was deployed in the NASA Goddard Space Environment Simulator - a 27 foot diameter vacuum chamber capable of temperatures as low as -180C. Once the beam was successfully deployed, it was instrumented for static beam bending and torsional stiffness tests and dynamic characterization.

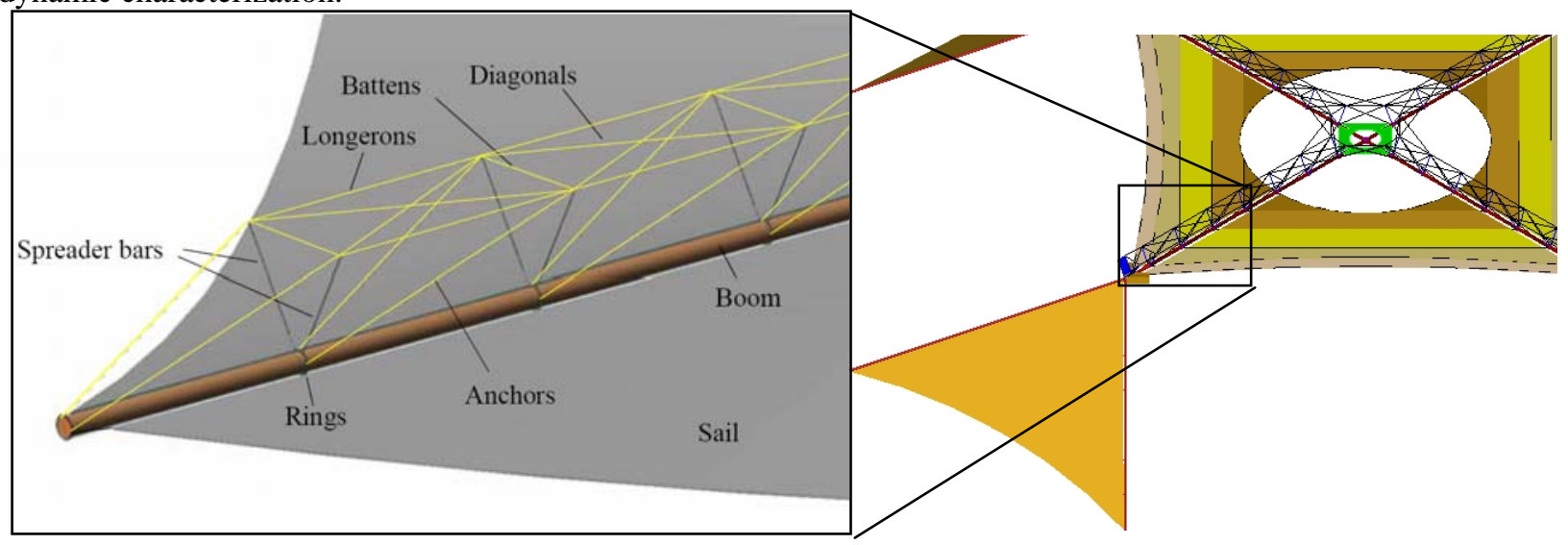

Figure 3. L'Garde Spreader Bar / Beam Assembly

The L'Garde beam design required connections between neighboring beams in the final assembly for the proper transfer of load from the sail through the beams (see Figure 3). As such, it was difficult to make an argument of symmetry and remove one beam section from the whole structure for testing. The positions of the Kevlar lines that would normally attach to adjacent beams determine the tensions in the entire spreader system. It was quickly learned that the structure is sensitive to changes in these stress levels and consequently the positions of these lines. In addition to the difficulties of placing these lines precisely to achieve the proper stress state, it was important to consider the impact of deformations due to temperature changes as the chamber was cooled to its final operational temperature for testing. Unfortunately, there was no remote method for determining the stress state of the structure once the chamber was sealed.

In addition to the boundary condition governed by the Kevlar line, the static and dynamic measurements of the 7 meter beam were complicated by the need for a gravity off-load system. The loads imparted on the sail beam during operation are generally very small. In order to minimize the mass of the system, only these loads could be considered in the design of the structure. Consequently, the loads imparted to the beam during ground testing were orders of magnitude greater than the operational loads and had to be dealt with appropriately. A gravity off-load system was designed to remove the gravity loads of the beam (and any additional attachments) using a dead-weight counterbalance system (see Figure 4). The off-load system also provided loads to simulate the forces on the sail outboard of the inner 10 meters (which the sail was designed to represent). The resulting static and dynamic tests were therefore measurements of a system where more than half of the mass participating was not associated with the test article itself.

The beam was successfully deployed and successfully tested for bending and torsional stiffness. Dynamic testing was unsuccessful, however, because of failure of the adhesive used to bond the accelerometer to the structure due to the low temperatures in the vicinity of the cold plates providing the thermal boundary condition. 
Following successful completion of the 7 meter beam tests, a 4 quadrant, 10 meter sub-scale solar sail was built for static and dynamic characterization the NASA Glenn Space Power Facility (SPF) at Plum Brook. The SPF is a 30 meter diameter vacuum chamber and was deemed the only location capable of full-scale testing of the 10 meter and 20 meter solar sail demonstrators with the capability of cooling the beams below their glass transition

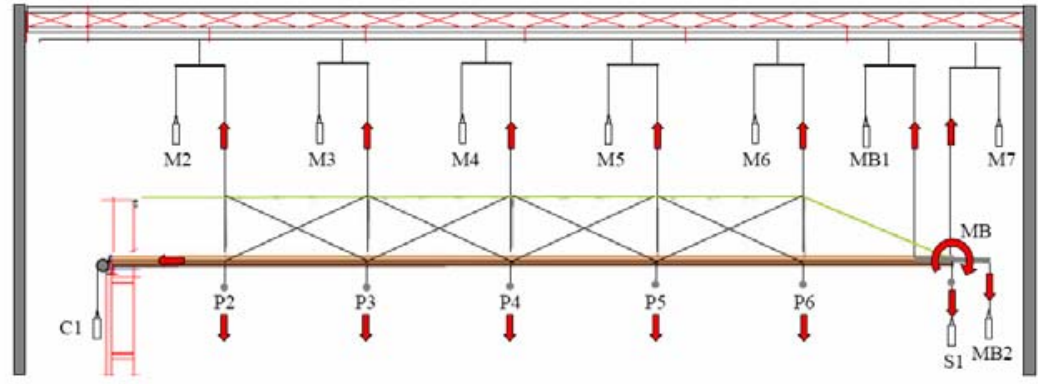

Figure 4. Gravity Off-Load and Outboard Load Application Details temperature. The sail was successfully deployed in the vacuum chamber and instrumented with retro-reflective targets on the sail membranes for static photogrammetry measurements. One beam tip was also instrumented with a series of load cells attached to linear actuators to perform bending and torsion tests on the beam. The linear actuators allowed remote operation to provide precise displacements to the boom while the load cell measured the results (and exceedingly small) response of the structure. Figure 5 shows the notional design intended to apply the
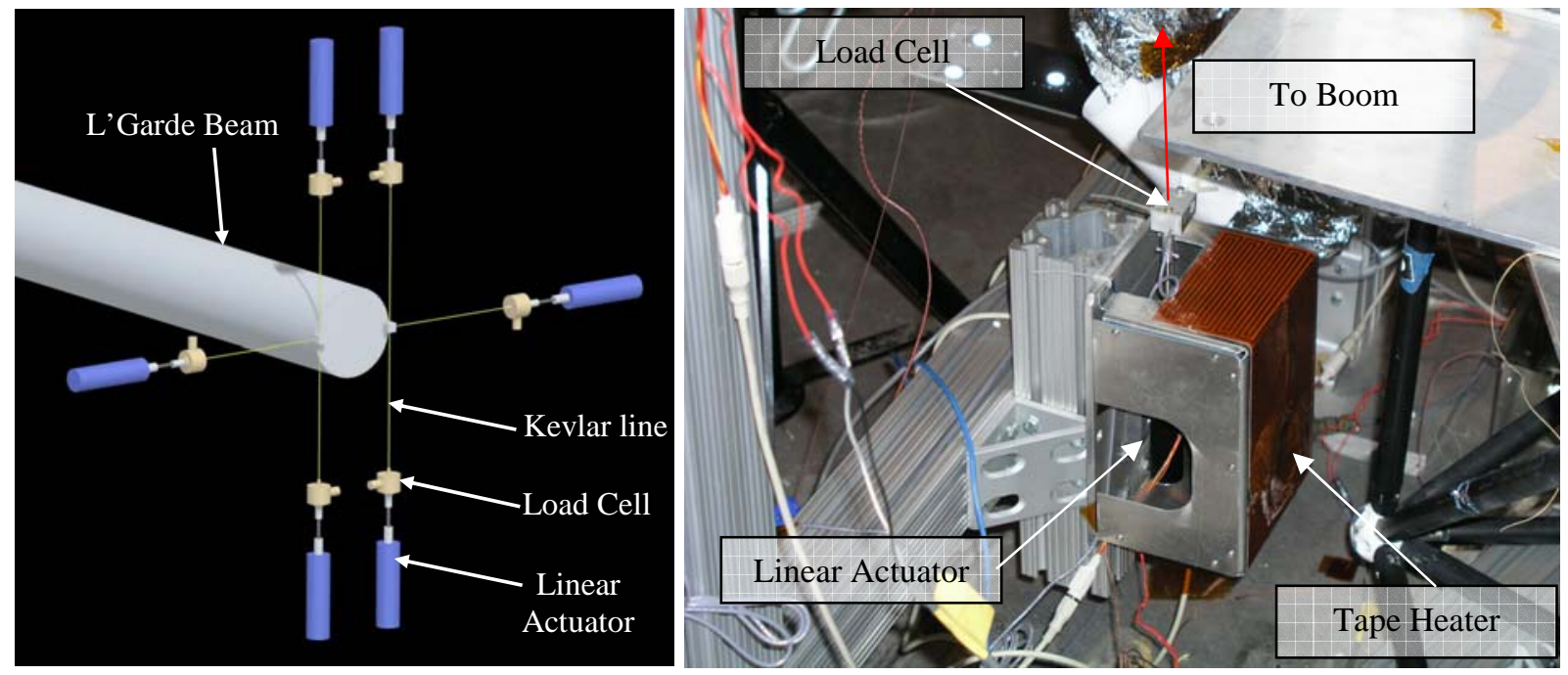

Figure 5. Notional Design of Load Application Apparatus, and Actual Implementation

loads and displacements for mechanical characterization and the final implementation of this idea. Cooling was provided to the beams by a series of capped square extrusions under the four beams. These were flooded with liquid nitrogen to decrease the temperature of the beam below the glass transition temperature. This impacted the design of the instrumentation significantly as the linear actuators were not capable of operating at the temperatures expected to be seen in the areas directly surrounding the cold plates. In order to mitigate the risk of these instruments failing, heater boxes were placed around the linear actuators to maintain an appropriate operational temperature. Unfortunately, a drain line for the cold plates was routed directly between the two lower actuator locations. This created a conduction path that had to be modified with various low thermal conductivity materials.

In the end, the static characterization tests were largely successful, despite numerous difficulties. During cooling of the beams, there was a significant change in their final position because of improper tension in the spreader bar system. This moved the test article out of the range of the actuators and made testing of the beam impossible from the lower two positions. Unfortunately, this was the preferred test condition, because it is the direction of bending of the structure due to solar pressure. It was discovered after the test that this would have been unsuccessful even if the test article had maintained position because the drain line moved enough during cooling to shear one of the lower heater boxes off of its supports. However, three of the remaining linear actuators and load cells were capable of applying displacements and measuring loads. Using the test apparatus in its final configuration several out-ofplane, in-plane and combined bending/torsion tests were successfully completed yielding estimates of the beam stiffness despite the improper boundary conditions in the test article. 


\section{Phase III - Sub-scale System Testing}

Following testing of the 10 meter sub-scale system, a 20 meter system was fabricated for deployment and static and dynamic characterization in the SPF. Again, the sail was deployed under vacuum conditions and then outfitted with retro-reflective targets for photogrammetry and laser vibrometry (see Figure 6).

Previous dynamic tests of solar sail subsystems had only targeted one quadrant for measurement. During the 20 meter tests, it was NASA Langley's intention to perform full-field measurements of the sail. Unfortunately, to do so with existing equipment would have required the vibrometer head to be mounted near the top of the SPF facility. It was determined that a different solution was necessary.

A Scanning Mirror System (SMS) was developed and

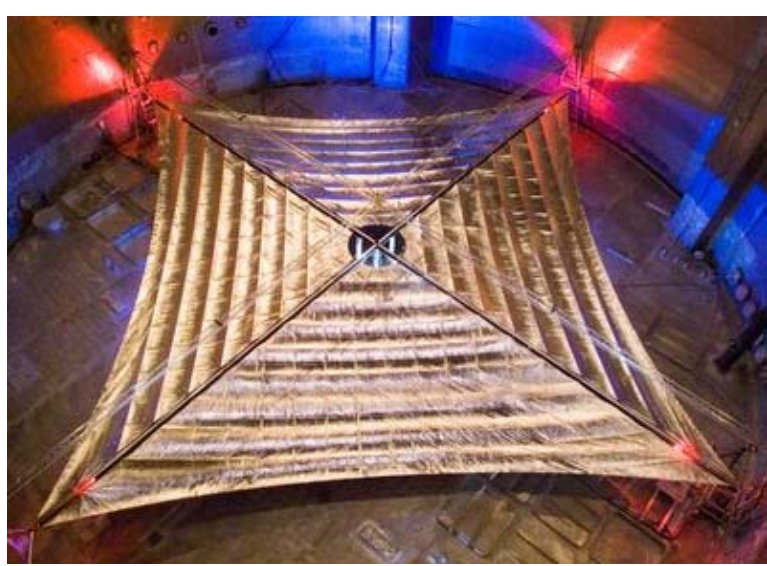

Figure 6. 20 meter Solar Sail Demonstrator in SPF

implemented for full-field measurements of the sail (see Figure 7). The SMS was mounted near the top of the SPF facility while the vibrometer head was mounted above the door frame of one of the large equipment doors. The measurement laser was directed to the SMS from the door frame. The SMS contained a stationary bounce mirror that reflected the measurement laser to a system of two orthogonal active mirrors. The active mirrors were used to scan the surface of the sail in order to find retro-reflective target locations and return the signal back to the vibrometer head. The SMS proved very capable and was successful in capturing full-field modal tests on two 20 meter solar sail systems.

Taking the information gleaned from the 10 meter tests, several modifications were made to the static test apparatus prior to their installation in the SPF. In order to measure the static capability of the sail system, two load and displacement fixtures were attached at opposing beams. This was intended to minimize rigid body rotations of the structure and maintain proper mirrored loading in the structure during all static tests. In order to mitigate any risks associated with displacement of the test article during cooling, two large two-axis linear stages were included in the design of the test fixture. These

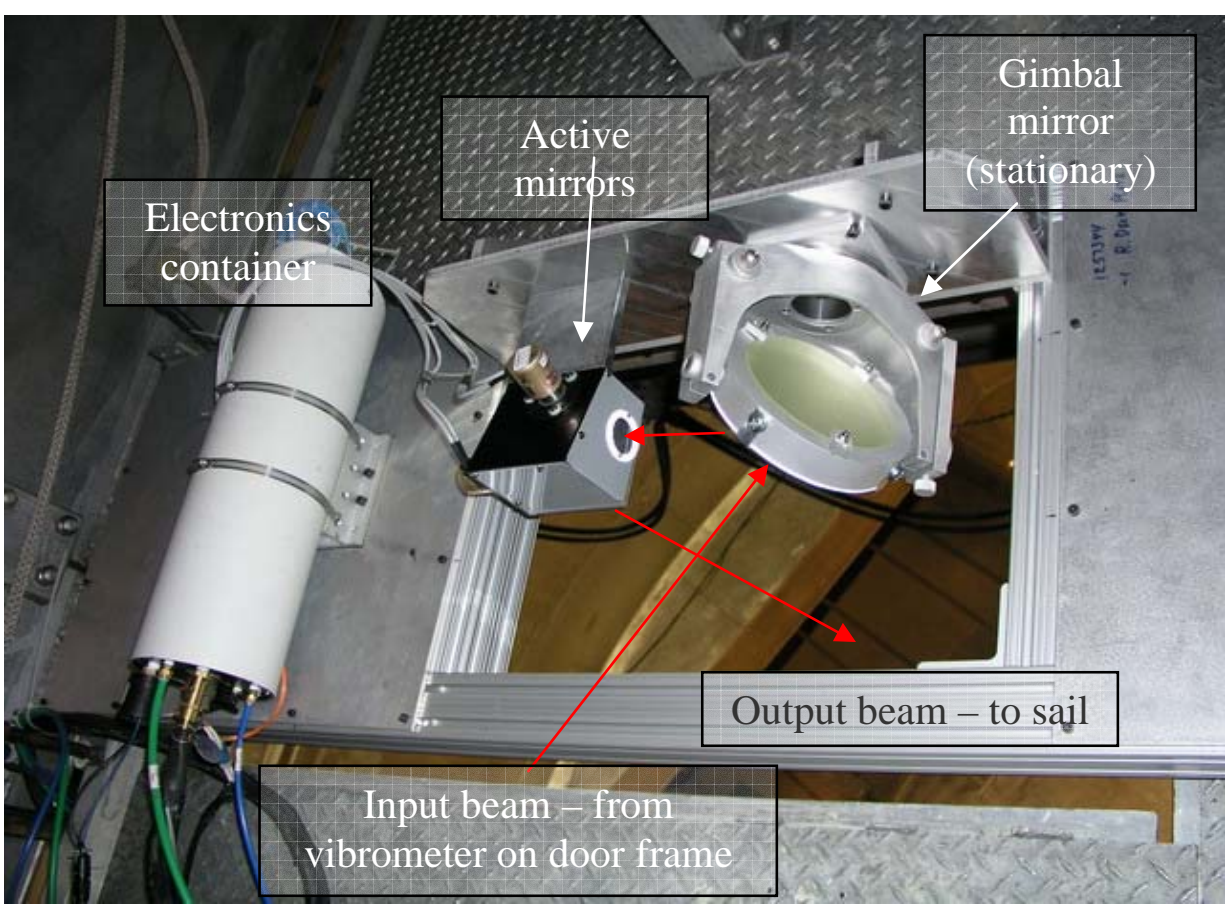

Figure 7. Scanning Mirror System (SMS) as Installed in SPF allowed the entire test apparatus to travel up to $300 \mathrm{~mm}$ in two orthogonal directions in order to compensate for possible locations changes of the beam end cap (see Figure 8). Thermal enclosures were again included to provide an adequate temperature environment for operation of the load cells and linear actuators.

During static testing of the 20 meter sail system, very little displacement of the beam end caps was measured. As a result, little adjustment was required to move the load apparatus in to position for testing. The full range of travel did prove useful in an attempt (unsuccessful) to measure the buckling load of the beam. 


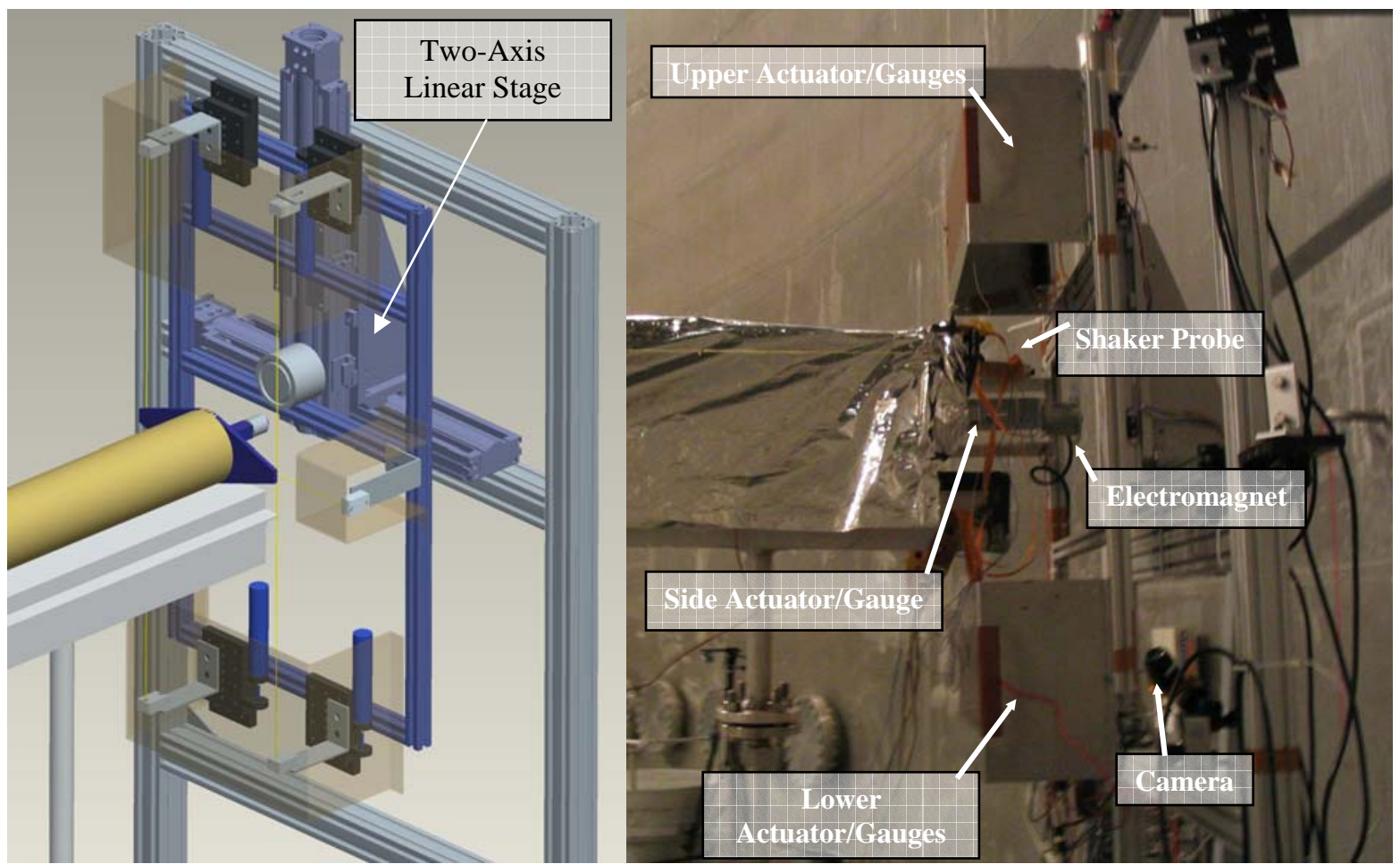

Figure 8. Notional and Actual Assemblies for Static and Dynamic Load Application

The movable load frame proved successful in measuring the static response of the 20 meter beam system in two bending planes and in torsion. However, when attempts were made to correlate the measured response of the system with that predicted by the finite element analysis, it became evident that there were several real-world issues that complicated the measurements.

First, the details of the gravity off-load system became first order effects in the prediction of the static response of the structure. The bars supporting the weight on one end and the structure on the other were made of thin-walled composite tubes with a diameter of $5 \mathrm{~mm}$. If the center support of these bars were mounted above the attachment position of the two outer connections, there was an effective restoring force as the bar tipped (in response to applied loading). Given the small loads applied to the structure, these restoring forces could become prohibitively large. The positions of these bars were not recorded during the tests so no conclusive arguments could be made regarding their reaction forces. As a result, the analysis had to consider both possibilities. The resulting predicted load displacement response did in fact bracket the measured response data leading to some confidence in the ability of the analysis model to predict the response of the structure. However, without direct measurements of the gravity off-load bar positions, no definitive evaluation of the actual load response could be determined.

Evaluation of the load response data also provided some insight into the nature of these very lightly loaded structures. The torsion response of the beam was particularly interesting because the structure was measured through a zero-load position (the nominal position). Torsion was applied to the structure by pulling alternately on linear actuators above and below the structure. The torsional stiffness of the structure followed the predicted response relatively closely at higher loads. However, as the torsion was reversed from one direction to the other (and as a result passed through the zero torsion position), an interesting response was recorded in the structure. The response of the beam seemed to be very nonlinear around the zero torsion position. It is expected that this is at least partially due to the low-load level response of the Kevlar supporting the loads at this point. Previous load/displacement evaluation of Kevlar has indicated a non-linearity in the neighborhood of zero load. It appears that the torsional stiffness of the structure at low load levels was governed solely by the stiffness of the boom and then increased significantly at higher stress levels as more of the Kevlar lines begin to react the load (see Figure 9).

\section{Conclusion}

Gossamer structures such as those required for solar sail missions can be particularly challenging to test in ground based testing environments. The operational loads of these structures can be exceedingly small and quickly 


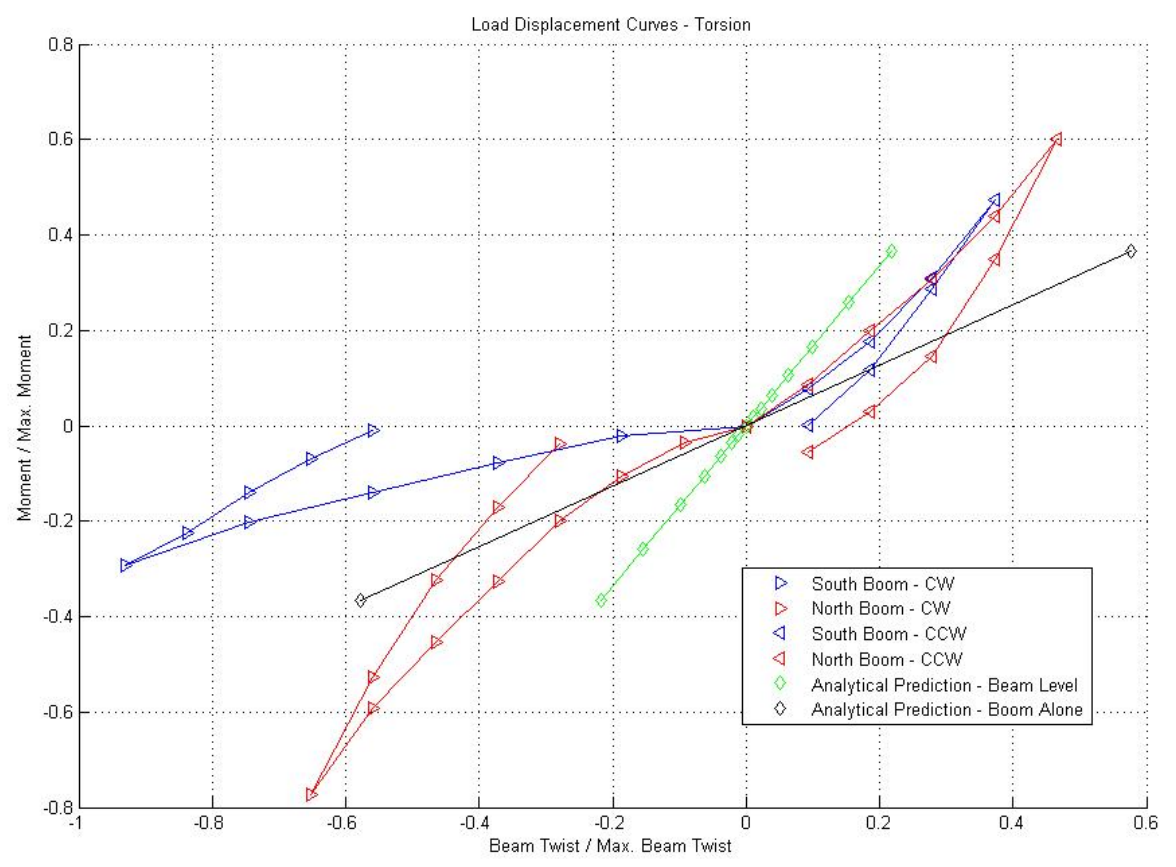

Figure 9. End Rotation Angle vs. Applied Torsion

surpassed by any fixtures used to install the hardware in a usable configuration. Even self-supporting loads experienced in 1-g gravity can often be overwhelming. Ground support equipment used to alleviate these gravity loads can generally be used with success, but then the ground support equipment must be included in any theoretical computations used to predict the response of the structure. In the end, the response of the entire system (including the ground support equipment) might mask the response of the actual test article considering that it might be dwarfed by all of the equipment used to render the test article operational on the ground. Test facilities can become particularly challenging and/or expensive to operate when trying to alleviate the above concerns while providing an environment conducive to testing the expected operation in a space-like environment. Finally, the materials used for gossamer structures must be well understood in low load operating range in order to effectively predict their operation. In particular, a system level response must consider materials included in the design that have no compressive capability.

\section{Acknowledgments}

The work described in this paper was funded in whole or in part by the In-Space Propulsion Technology Program, which is managed by NASA's Science Mission Directorate in Washington, D.C., and implemented by the In-Space Propulsion Technology Office at Marshall Space Flight Center in Huntsville, Alabama. The program objective is to develop in-space propulsion technologies that can enable or benefit near and mid-term NASA space science missions by significantly reducing cost, mass or travel times.

\section{References}

'Wright, J., Space Sailing, Taylor and Francis Publishers, 1992.

${ }^{2}$ McInnes, C. R., Solar Sailing: Technology, Dynamics, and Mission Applications, Springer-Praxis Series in Space Science and Technology, 1999.

3Chmielewski, A. B., “Advanced Concepts,” Gossamer Spacecraft: Membrane and Inflatable Structures Technology for Space Applications, Edited by C.H.M. Jenkins, Progress in Astronautics and Aeronautics, Vol. 191, American Institute of Aeronautics and Astronautics, Reston, VA, 2001.

${ }^{4}$ Salama, M., McInnes, C. R., and Mulligan, P., “Gossamer Spacecraft Technology,” Gossamer Spacecraft: Membrane and Inflatable Structures Technology for Space Applications, Edited by C.H.M. Jenkins, Progress in Astronautics and Aeronautics, Vol. 191, American Institute of Aeronautics and Astronautics, Reston, VA, 2001.

${ }^{5}$ West, J. L. and Derbès, B., "Solar Sail Vehicle System Design for the Geostorm Warning Mission,” 41st AIAA/ASME/ASCE/AHS/ASC Structures, Structural Dynamics \& Materials Conference, AIAA-2000-5326, 2000. 
${ }^{6}$ West, J. L., “The Geostorm Warning Mission: Enhanced Opportunity Based on New Technology,” 14th AAS/AIAA Space Flight Mechanics Conference, AAS 2004-102, 2004.

'Lichodziejewski, D., Derbès, B., West, J., Reinert, R., Belvin, K., and Pappa, R., "Bringing an Effective Solar Sail Design Toward TRL 6,” 39th AIAA/ASME/SAE/ASEE Joint Propulsion Conference and Exhibit, AIAA 2003-4659, 2003.

${ }^{8}$ Lichodziejewski, D., Derbès, B., Reinert, R., Belvin, K., Slade, K., and Mann, T., "Development and Ground Testing of a Compactly Stowed Scalable Inflatably Deployed Solar Sail,” 45th AIAA/ASME/ASCE/AHS/ASC Structures, Structural Dynamics \& Materials Conference, AIAA-2004-1507, 2004.

${ }^{9}$ Greschik, G. and Mikulas, M.M., "Design Study of a Square Solar Sail Architecture,” Center for Aerospace Structures, University of Colorado, Boulder, CO.

${ }^{10}$ Lichodziejewski, D., Derbès, B., Slade, K., and Mann, T., "Vacuum Deployment and Testing of a 4-Quadrant Scalable Inflatable Rigidizable Solar Sail System,” 46th AIAA/ASME/ASCE/AHS/ASC Structures, Structural Dynamics

\& Materials Conference, AIAA-2005-2122, 2005. 